\title{
Pensando a temática ambiental de forma mais crítica e reflexiva: a contribuição de Héctor Ricardo Leis
}

Evandro de Oliveira

Doutorando em Ciências Humanas

\section{RESUMO}

O artigo propõe uma revisão das principais ideias do pesquisador Héctor Ricardo Leis com relação a temas ambientais. $O$ autor procura pensar o meio ambiente sob várias óticas, ampliando dessa forma a interdisciplinaridade que as questões ambientais necessitam para serem estudadas. Aporta inúmeras contribuições ao setor ambientalista, pois trata temas como amor, igualdade e ética sob a perspectiva ambiental. Naturalmente, suas percepções também recebem críticas, apresentadas com o intuito de contribuir com suas reflexões. Por fim, nota-se os diversos caminhos que Leis oferece para a consideração dos temas ambientais e também fica notório que, sendo o ambientalismo um assunto complexo, se requer de mais autores que, como Leis, pensem o meio ambiente de forma complexa.

Palavras-chave: Ambientalismo; Interdisciplinaridade; Héctor Ricardo Leis. 


\title{
Thinking the environmental theme in a more critical and reflective way: Héctor Ricardo Lei's contribution
}

\author{
Pensando la temática ambiental de forma más crítica y reflexiva: la \\ contribución de Héctor Ricardo Leis
}

\begin{abstract}
The article proposes a review of the main ideas of the researcher Héctor Ricardo Leis regarding environmental matters. The author tries to think the environment from different perspectives, thus expanding the interdisciplinarity that environmental issues needs to be studied. The author gives countless contributions to the environmental sector, as it deals with themes such as love, equality and ethics from an environmental perspective. Of course, his perceptions also receive criticism, presented in order to contribute to his reflections. Finally, it is noted the various paths that Leis offers for the consideration of environmental issues and it is noticeable that, since environmentalism is a complex subject, it is required that more authors, such as Leis, think the environment in a complex way.
\end{abstract}

Keywords: Environmentalism; Interdisciplinarity; Héctor Ricardo Leis.

RESUMEN

Este artículo propone una revisión de las principales ideas del investigador Héctor Ricardo Leis respecto a los temas ambientales. El autor trata de pensar el medio ambiente desde ópticas diversas, ampliando, de esa forma, la interdisciplinaridad que las cuestiones ambientales necesitan para ser estudiadas. El autor aporta muchas contribuciones al sector ambientalista, pues trata temas como amor, igualdad y ética desde la perspectiva ambiental. Por supuesto, también se hacen críticas a las posturas de Leis, con la intención de contribuir con sus reflexiones. Se puede concluir que Leis apunta caminos para la consideración de los temas ambientales; asimismo, como el ambientalismo es un asunto complejo, se necesita de mayor número de autores que, como él, piensen el ambiente de forma compleja.

Palabras-clave: Ambientalismo; Interdisciplinaridad; Héctor Ricardo Leis.

\section{INTRODUÇÃO}

O presente artigo tem por objetivo expor as contribuições que o autor Héctor Ricardo Leis formulou com relação ao tema ambiental. Além disso, pretende também refletir sobre esses saberes, com o intuito de melhor compreendê-los e identificar seus possíveis subsídios para a consideração da questão ambiental.

Héctor Ricardo Leis nasceu em Buenos Aires em 1943. Estudou matemática, psicologia, filosofia e sociologia na Universidade de Buenos Aires. Veio ao Brasil em 1977, onde se licenciou em Ciências Sociais pela Pontifica Universidade Católica do Rio de Janeiro. Nesta mesma universidade fez seu doutorado em Filosofia, além de ter feito mestrado na University of Notre Dame (EUA). De volta para a Argentina, foi professor de Ciência Política e do Ciclo Básico na Universidade de Buenos Aires (UBA), e de Filosofia na Universidad Nacional de Rosario. Em 1989 voltou ao Brasil, assumindo a docência de 
Relações Internacionais na PUC/RJ. A partir de 1992 esteve vinculado ao Departamento de Ciências Sociais da UFSC, passando a lecionar tanto na graduação quanto no mestrado e doutorado em Sociologia Política e no Doutorado Interdisciplinar em Ciências Humanas.

No Doutorado Interdisciplinar em Ciências Humanas, foi coordenador por mais de cinco anos. O Professor Leis tornou-se um dos mais importantes defensores da abordagem interdisciplinar nas ciências humanas e ambientais. Algo importante a ser destacado é que Héctor Leis, antes de iniciar sua trajetória acadêmica, teve uma ativa participação política na Argentina, primeiro no Partido Comunista, depois no Peronismo, e, finalmente, numa das organizações revolucionárias que optaram pela luta armada, o que o levou ao exílio e a ser um refugiado político das Nações Unidas. Foi membro do Club de Cultura Socialista Pancho Aricó e do Fórum de ONGs ambientalistas da ECO-92. Em 1989 estabeleceu-se definitivamente no Brasil, onde obteve a cidadania em 1992. Leis faleceu no dia seis de setembro de 2014 .

Dentre os vários artigos e livros publicados por Héctor Leis, optou-se por utilizar, nesse trabalho, as publicações que discutem a temática ambiental. $\mathrm{O}$ artigo está dividido em cinco seções, cada um deles procura enfatizar e elucidar as colaborações do autor sobre o meio ambiente; e por último presentam-se as considerações finais.

\section{AMBIENTALISMO COMO MOVIMENTO VITAL HISTÓRICO}

Uma das primeiras contribuições de Leis para se pensar o tema ambiental foi o de olhar o ambientalismo como um movimento vital histórico. Primeiramente Leis (2014), baseando-se em Viola (1992), explicita que o ambientalismo se encaixa sob três perspectivas distintas: como grupo de pressão ou interesse, como um novo movimento social ou como movimento histórico. De acordo com a primeira óptica, o ambientalismo é um grupo que se encontra dentro do sistema político e por isso compreende que os desafios ambientais não são um grande perigo para a sociedade; tampouco questiona questões normativas inerentes ao sistema social atual. $\mathrm{O}$ ambientalismo como movimento social tem a característica de ser um ator que critica o modelo de sociedade atual e, ao mesmo tempo, é uma alternativa a esse modelo; apresenta-se de um modo fortemente normativo. A premissa do ambientalismo como movimento histórico se caracteriza por ser a que mais se aproxima da complexidade do ambientalismo, pois o movimento histórico 
ressalta que o modelo de sociedade atual é insustentável a médio e longo prazo, e além disso critica o consumismo e o crescimento econômico sem limites, existentes atualmente.

No entanto Leis (2014) vê o ambientalismo como um movimento histórico e vital, ou seja, além de o ambientalismo possuir as características de um movimento histórico, também tem as de um movimento vital. Para Leis e D’Amato (1996), esse movimento vital é constituído por diversas dimensões sinérgicas que apontam para várias direções, formatando um molde rico em diversidade cultural e força histórica. Diante disso, Leis (2014) ressalta que o ambientalismo visto como movimento histórico-vital enfatiza as suas várias expressões e interações, dando importância aos setores moderados e radicais, aos técnicos e políticos, cientistas e empresários, etc. Essa face histórico-vital do ambientalismo não estimula a cooperação nem o conflito entre os atores existentes, mas tenta conceber formas tanto conflituosas como cooperativas de mutação comportamental dos setores e indivíduos, com o propósito de encontrar uma melhor relação entre sociedade e natureza. Em suma, o ambientalismo visto como movimento histórico-vital permite compreender a complexidade que está contida no próprio ambientalismo, pois o mesmo é marcado por diversas características e para identificá-las e entendê-las é necessário ver o ambientalismo como movimento histórico-vital.

\section{AS SEIS DIMENSÕES HISTÓRICAS DO AMBIENTALISMO}

Para Héctor Leis, o ambientalismo possui seis momentos históricos que fazem parte de seu desenvolvimento, os quais são: sua fase estética, a da ciência, da sociedade civil, do sistema político, do mercado e da espiritualidade.

Iniciando com a dimensão estética, Leis (1996) defende que o início do paradigma ecológico acontece a partir do século XIX. Segundo Leis (2014), ideias, saberes e sensibilidades que tenham relação com o tema ambiental formatam o que ele denomina de fase estética do ambientalismo. Essa dimensão é composta por criações intelectuais advindas de políticos, cientistas e artistas. A partir do final do século XVIII, inicia-se a criação de saberes que questionam a dominação do homem sobre a natureza e também ocorre a criação das primeiras concepções que mais tarde dariam origem ao conceito de ecologia. Essas percepções resumem-se nas obras de Gilbert White e Carl Linnaeus que, décadas mais tarde, já no século XIX, tiveram muita influência na relação entre o homem e a 
natureza. Entretanto, a fase estética do ambientalismo teve início após o encontro entre os naturalistas -que tinham o interesse em conhecer melhor a natureza-, e as revoluções francesa e americana que reivindicavam a igualdade entre os homens. Leis (2014) afirma que muitas ligações existiram entre naturalistas, abolicionistas da escravidão e os ativistas contra a violência praticada contra os animais. A militância contra a crueldade praticada aos animais é o aspecto mais notório do começo do ambientalismo. Outro segmento importante dessa fase foi a criação das primeiras áreas de preservação ambiental do mundo, localizadas nos Estados Unidos.

No século XX o ambientalismo começou lentamente a sair da sua fase estética, dando lugar ao debate entre preservacionistas e conservacionistas que, devido principalmente a conflitos políticos e guerras mundiais foram interrompidas. Com isso, o ambientalismo volta com força somente após a Segunda Guerra Mundial, entrando em sua segunda fase, o da ciência (LEIS, 2014).

A dialética entre preservacionistas e conservacionistas é retomada basicamente por cientistas. Um fato ilustrativo do domínio acadêmico sobre as questões ambientais ocorreu em 1948, quando é criada a União Internacional para a Proteção da Natureza por um grupo de cientistas. Outro ponto a ser destacado foi que as duas primeiras conferências sobre temas ambientais realizadas após a segunda guerra (Conferência Científica das Nações Unidas sobre Conservação e Utilização de Recursos, e a Conferência Técnica Internacional sobre a Proteção da Natureza) foram organizadas por pesquisadores. Segundo Leis (2014), estes encontros representam as primeiras aparições do ambientalismo no cenário mundial. No entanto, neste aspecto discorda-se parcialmente de Leis (2014). Apesar destas conferências ajudarem na ascensão do ambientalismo no cenário global, a questão ambiental também começou a ganhar notoriedade mundial a partir da década de 1950 devido a alguns acidentes ambientais que chamaram a atenção do mundo, devido aos impactos socioambientais advindos dos mesmos. Alguns exemplos são: na Inglaterra, em Londres, o elevado uso de carvão para a produção de energia teve como consequência o fenômeno chamado smog; e também ocorreu a contaminação da Baía de Minamata, no Japão, em 1956 (SEIFFERT, 2007). Entende-se que estes acidentes auxiliaram na extensão da discussão ambiental a nível mundial.

A criação do Clube de Roma e a publicação do relatório "Os Limites do Crescimento" demonstram ainda mais a força da ciência no ambientalismo nessa época. A ecologia 
também foi uma disciplina muito importante para o estudo de questões ambientais, devido ao seu caráter interdisciplinar, que permitiu produzir conhecimentos científicos verdadeiramente inovadores (LEIS, 2014). Outro importante acontecimento na época aconteceu em 1962, quando a bióloga Rachel Carson publicou o livro Silent Spring (Primavera Silenciosa), no qual retratava os perigos que o uso do Dicloro Difenil Tricloroetano (DDT) trazia para o meio ambiente (SEIFFERT, 2007).

Seguindo na perspectiva de Leis (2014), após o importante papel da ciência no ambientalismo, surgem, na década de 1960, as ONGs para dar à questão ambiental uma nova face. A primeira ONG de faceta mundial foi a World Wildlife Fund (WWF) criada em 1961. Essa ONG realizava projetos de caráter mais conservacionistas, voltados a espécies individuais, áreas virgens, etc.

É importante frisar que nos anos 60 e 70 várias pautas políticas e sociais demandavam uma ampla participação da população e ativismo individual, podendo se destacar a contracultura dos hippies, os negros e até a guerrilha do terceiro mundo. $\mathrm{O}$ ambientalismo se beneficiou muito desse período revolucionário, mas se destaca que o mesmo tinha suas próprias características e valores, distinguindo-se dos outros movimentos. Além disso, o movimento ambiental possui valores únicos, ou seja, o ambientalismo e seus propósitos não contradizem outros movimentos; ao contrário, permitem que outros movimentos se nutram do ambientalismo ou aumentem seu campo de ação (LEIS, 2014). Um exemplo disso, na atualidade, são as ecofeministas, que seria uma ramificação do feminismo que procura estudar a relação das mulheres com a natureza.

Muitas ONGs foram criadas nessa época, mas além da WWF, duas delas chamaram a atenção devido principalmente ao seu modo de atuação: o Greenpeace e os Friends of the Earth. O Greenpeace teve por característica a ação direta, embora não-violenta, já os Friends of the Earth não tinham uma chefia centralizada, mas davam oportunidade para que os grupos locais tomassem suas próprias decisões (LEIS, 2014).

Com a ajuda das ONGs, os temas ambientais começaram a ser difundidos ainda mais no mundo, e com isso seu dinamismo e apoio popular ganhou mais força. As ideias ambientais trazidas pelas ONGs são um resultado da mudança perceptiva da sociedade com relação ao meio ambiente (LEIS, 2014). As ONGs também estiveram presentes em Estocolmo 72 e Rio 92; presume-se que em Estocolmo compareceram cerca de 250 ONGs, já na Eco-92 foram quase 2.000 ONGs ambientalistas. 
Para Leis (2014), as três vertentes explicitadas até agora (estética, ciência e ONGs) representam o lado ético-utópico do ambientalismo. No entanto o autor salienta que as dimensões política e econômica do movimento ambientalista o transformaram em um movimento realista-utópico.

A chegada da ecologia ao Estado iniciou-se a partir do momento em que muitos ambientalistas começaram a politizar-se. Outro aspecto que impulsionou o ambientalismo a entrar na política foi a conferência de Estocolmo. Para deixar mais claro esse aspecto, vale ressaltar o número de agências estatais ambientais antes e depois de Estocolmo; antes da conferência apenas 12 países contavam com esse tipo de serviço, depois do evento mais de 140 países tinham criado seus órgãos administrativos ambientais (LEIS, 2014).

Uma singularidade do movimento ambiental é não ser nem de esquerda nem de direita. Isso se deve ao fato do ambientalismo ser um movimento de alta complexidade, que pode se beneficiar de ideias de direita ou esquerda, de privatizações ou nacionalizações. Essa gama de opções reflete a alta complexidade dos problemas ambientais que, para serem solucionados, precisam não apenas de meios técnicos, mas também de atitudes políticas e éticas. Além disso, o movimento ambientalista parte do pressuposto que nem a direita política, nem a esquerda são capazes de solucionar as problemáticas ambientais (LEIS, 2014).

A política ambiental nos anos 1970 tinha os seguintes princípios: ecologia, responsabilidade social, democracia direta e não-violência. Esses valores geralmente aparecem de forma implícita, e sempre estão conectados uns aos outros nas demandas políticas. Uma grande vantagem do ambientalismo na questão política era que o mesmo não era inimigo de ninguém, todos os lados políticos poderiam tanto se beneficiar de ideias advindas do mesmo, como simultaneamente receber críticas (LEIS, 2014).

A entrada do movimento ambiental na política se concretiza através da criação de partidos e a institucionalização de órgãos ambientais. Um dos primeiros partidos ambientalistas a ser criado foi, em 1972, em Nova Zelândia. Após isso, vários outros países fizeram o mesmo. Esses partidos tiveram uma rápida ascensão, pelo fato dos outros partidos terem fracassado em solucionar ou amenizar os problemas ambientais. É importante frisar que a democracia e o ambientalismo possuem uma correlação muito significativa e importante para a sociedade (LEIS, 2014). 
Na reunião de Estocolmo, em 1972, a economia fez parte de algumas discussões, no entanto os ambientalistas não aceitavam que o crescimento econômico continuasse, e propugnaram o crescimento zero, proposta que não foi aceita, principalmente pelos países subdesenvolvidos, que acreditavam que o crescimento econômico a qualquer custo era um bom caminho para o desenvolvimento. Com isso, foi proposto por Maurice Strong o conceito de ecodesenvolvimento, que propõe um desenvolvimento econômico que seja ambientalmente correto; em outras palavras, o crescimento econômico continuaria, mas respeitaria a natureza, gerando o menor impacto e poluição ambiental possível, além de esforçar-se para preservar os recursos naturais. O ecodesenvolvimento defendia um desenvolvimento endógeno, ou seja, partindo do local; essa e outras ideias embutidas no conceito foram consideradas "radicais" demais pelos grandes empresários, que combateram o conceito. Diante disso, o conceito ecodesenvolvimento foi deixado de lado e a economia continuou sem dar atenção ao meio ambiente.

Mas, a partir da década de 1980, a temática ambiental ganha cada vez mais força, e com isso, a economia não pode mais ignorar este movimento. O diálogo entre economia e meio ambiente aconteceu por intermédio do conceito de desenvolvimento sustentável. O caminho para se criar esse conceito iniciou-se em 1983 quando a assembleia geral da ONU criou a Comissão Mundial sobre o Meio Ambiente e Desenvolvimento, com a meta de elaborar propostas inovadoras e realistas. Dos estudos dessa comissão surgiu o relatório Nosso Futuro Comum, e nele apareceu o termo desenvolvimento sustentável. Esse conceito teve o objetivo de ser mais realista, com propostas menos críticas à economia, juntando desenvolvimento e meio ambiente (LEIS, 2014). Portanto, nos anos 80 e 90, o desenvolvimento sustentável foi adotado como um estilo de gestão empresarial, uma vez que o conteúdo pragmático do conceito (e não seu lado ético) chamou a atenção dos empresários, que viram ali uma oportunidade de perpetuar a geração de riqueza sem muitos prejuízos financeiros. Uma evidência disso foi a criação do conselho empresarial para o desenvolvimento sustentável criado em 1990 (LEIS, 2014).

É importante lembrar que outro conceito também surgiu da conexão economia/meio ambiente, o termo economia ecológica, criado por Georgescu-Roegen muitos antes do interesse dos empresários pela questão ambiental. A economia ecológica realiza uma crítica radical à economia ortodoxa, ressaltando principalmente a insustentabilidade do crescimento econômico (LEIS, 2014). 
Outro conceito não destacado por Leis em seu livro, mas que surgiu na década de 1970, foi o termo economia ambiental. A economia ambiental tem por objetivo atribuir valor aos recursos naturais, em outras palavras, a finalidade da economia ambiental é olhar a questão ambiental sob a perspectiva da economia convencional, sob o signo monetário. A economia ambiental irá valorizar o meio ambiente não pelas suas qualidades intrínsecas, mas sim pelo seu possível valor em dinheiro (CAVALCANTI, 2010).

Nessa medida, a incorporação do ambientalismo pelo mercado, de maneira oportunista e instrumental, concretizou-se nas décadas de 80 e 90 . Após isso vem a última fase ao ambientalismo, a dimensão espiritual.

Com relação à fase espiritual do ambientalismo, Leis (1996) explica que um ambientalismo laico não tem condições de perceber diversos fatores que causam a problemática ambiental; um deles, por exemplo, é o próprio cristianismo. Leis (2010), baseando-se em White, destaca que a ciência e a técnica não são as únicas responsáveis pela crise ambiental, e que o cristianismo teve grande parcela de culpa nessa questão ao introduzir no ocidente dogmas religiosos que tinham por escopo o ser humano, deixando a natureza à margem das premissas religiosas. Em suma, a crença em um homem feito à semelhança de Deus tirou da natureza seu valor e propiciou a sua dilapidação em prol do ser humano.

Após a Eco-92, o setor religioso começa a ocupar o espaço deixado pelo setor empresarial no ambientalismo (LEIS; D’AMATO, 1994). Alguns exemplos da conexão entre religião e ambientalismo são enfatizados por Leis (2014), a destacar: a ONG ambientalista WWF começa a promover diversos encontros entre distintas religiões para discutir o tema meio ambiente; o grupo ambientalista Earth First se apoia amplamente em valores religiosos provindos do budismo, do hinduísmo, do taoísmo, do paganismo e da espiritualidade dos índios norte-americanos; e por último o movimento Chipko Andolan na Índia que ficou famoso pelas atitudes das mulheres em abraçar as árvores para impedir o desmatamento. As raízes históricas deste movimento encontram-se profundamente entrelaçadas com questões espirituais.

Em resumo, Leis (1996) defende que a força do ambientalismo encontra-se em sua raiz espiritual, mas apesar disso, todas as suas dimensões são importantes e necessárias para este movimento vital histórico. 


\section{AMOR, IGUALDADE, HIERARQUIA E MEIO AMBIENTE}

Outra importante contribuição de Leis para se refletir sobre temas ambientais é a relação que estabelece entre amor e meio ambiente. Leis (2014), tendo por base o autor Michel Serres, elucida que os contratos sociais criados pelo homem o desconectaram do mundo e do tempo. Diante disso, essa re-ligação entre humanos e natureza não será feita pela política nem pela ciência, mas sim pelo amor. É apenas no amor que se pode encontrar um meio para estabelecer vínculos do homem para com o homem, e deste para com a natureza. Além disso, Leis (1999) parte da premissa que essa crise ambiental deixa notório o vazio ético e religioso da modernidade. A partir disso, é imprescindível a criação de meios que envolvam os seres humanos moral e espiritualmente com a natureza, e isso pode ser feito por uma ética ambiental que tenha como elemento primordial também o amor. Notase a importância que Leis atribui ao amor para a ética ambiental e para uma nova conexão entre homem e meio ambiente. O autor define amor como, "relacionamento gratuito com e entre os seres humanos e não-humanos para que cada um deles realize sua finalidade em liberdade" (LEIS, 1999, p. 02). O amor tem o poder de despertar a cooperação entre os seres humanos, e não apenas isso, o ethos amoroso ajudaria a superar os conflitos oriundos de diferenças identitárias e os antagonismos dos distintos interesses materiais (LEIS, 2010).

Porém o autor alerta que, para esse amor ocorrer na sociedade, é necessário que suceda uma conversão, ou seja, o amor só conseguirá realizar as ideias anteriormente explicitadas se uma mudança radical de comportamento e de disposição moral acontecer. Algo que ainda os seres humanos não têm condições sociais e políticas para realizarem (LEIS, 2010).

No entanto, Leis (2014) argumenta que o princípio da hierarquia traz à tona fatores que são essenciais para suscitar avanços na operacionalização do amor. Um exemplo destacado por Leis (1996) é que quando a hierarquia não é apenas dominação, esta permite que os seres humanos se assumam como interdependentes, e isso propicia que os homens cumpram uma ordem automaticamente, de maneira voluntária e cooperativa. Diante disso, para Leis (2010) a hierarquia sobre bases autênticas, ou seja, não sendo dominação pura, possibilita a empatia amorosa.

Outro argumento salientado pelo autor em defesa do princípio hierárquico respalda que as ambições humanas precisam ser controladas por agentes externos para que se 
possam construir boas condições para a sociedade humana. Usando autores como Hobbes e Tocqueville ele procura reforçar sua posição. Primeiramente com Hobbes, Leis chama a atenção para o Estado de natureza, e explica que a partir dos momentos em que os homens desejam a mesma coisa, e essa coisa não pode ser usada por todos, os seres humanos entrarão em conflito. A igualdade e a liberdade, se não forem controladas por um poder absoluto (o Leviatã) deixam os homens à deriva da escassez, levando-os consequentemente à guerra. Já Tocqueville, explicado por Leis, afirma que a democracia não se sustenta apenas no amor e igualdade das pessoas, mas também na abundância de terra, ou seja, não havendo escassez. Diante disso, nota-se que para Leis a hierarquia não propicia somente certas bases para a empatia amorosa, mas também auxilia a preservar o meio ambiente.

Ao mesmo tempo em que Leis defende a hierarquia, ele concebe muitas críticas com relação à igualdade. Se por um lado a hierarquia faz com que ordens sejam assumidas voluntariamente, por outro a igualdade permite a desresponsabilização dos indivíduos com relação aos problemas comuns. A igualdade foi criada pelos gregos para ser usada na política, mas na modernidade, a igualdade foi naturalizada ao ponto de qualquer desigualdade existente ser considerada injustiça. Esse princípio se caracteriza por escolher um valor e negar outro; o apego das pessoas à igualdade implica também o desinteresse pela realidade tal como ela se encontra. A materialização da igualdade tal como ela está estabelecida na sociedade contemporânea não foi realizada pelo Estado, mas sim pelo mercado, com o intuito de transformar tudo em mercadoria (LEIS, 2010). No entanto, entende-se que além do mercado querer transformar tudo em mercadoria ao naturalizar a igualdade, o mercado também promoveu a igualdade no quesito "todos somos consumidores", o que implicou no aumento no número de consumidores.

Essa constante ênfase na igualdade operacionalizada na modernidade não respeita distinções culturais, nem os méritos, nem as identidades. A igualdade congela as relações humanas, já a hierarquia tem por característica o retorno dessa relação, pois o que é superior em uma instância pode se tornar inferior em outra, possibilitando assim o estabelecimento de boas relações sociais entre os indivíduos (LEIS, 2014).

O princípio igualitário abre a possibilidade para os atores sociais acreditarem que são donos dos seus próprios destinos. Devido a isso, as pessoas criam relações facultativas entre si; mas vale lembrar que a maioria das relações sociais não possuem essa faceta, não 
obstante são hierárquicas, como por exemplo a relação entre pais e filhos, alunos e professores, etc. Em suma, Leis, parafraseando Nietzsche, explica que assim como existe uma hierarquia que se foca apenas na dominação, existe uma igualdade degradada que suscita a homogeneidade e o totalitarismo (LEIS, 2014). Essa igualdade criticada por Leis, também se reflete nos padrões culturais da modernidade que, além de estabelecer uma cultura hegemônica através da igualdade, também cogita extinguir as culturas locais, pois são diferentes e não iguais. Além disso, Leis (2014) chama a atenção para o fato desta igualdade existir somente entre os seres humanos, e não para com os outros seres vivos; em outras palavras, um ser humano é igual a outro, mas um ser vivo não é igual a uma pessoa; logo, se qualquer outro ser vivo não é igual ao homem, também não possui direito, pois o direito é algo reservado somente para os iguais. Diante disso, a igualdade reforça ainda mais a separação entre o homem e a natureza ao obscurecer as relações não racionais existentes entre humanos e não humanos.

\section{ÉTICA ECOLÓGICA}

Conforme Leis (1996), o ambientalismo tem por prioridade a mutação de ideais e comportamentos de inspiração ética para enfrentar a crise ecológica. Contudo, Leis e D’Amato (1994) sustentam que essa ética deve ser complexa e multisetorial, recuperando o sentido espiritual da humanidade.

Mas a ética ecológica existente possui diversas facetas e vertentes. Leis (1996;1994) tenta expor em seus artigos as principais características dessa ética ecológica.

O primeiro carácter da ética ecológica é encontrar-se no meio de visões antagônicas, entre um ethos artificial e outro natural. De forma similar encontra-se o ambientalismo, que se situa entre o otimismo -que considera que o crescimento econômico vai resolver os problemas ecológicos-, e o pessimismo, que preconiza que estamos diante de um verdadeiro colapso ambiental. De qualquer forma, o esquema teórico apresentado por Leis permite compreender as principais correntes da ética ecológica. No quadro 1, Leis contextualiza a ética ecológica. 
Quadro 1: Vertentes da Ética Ecológica

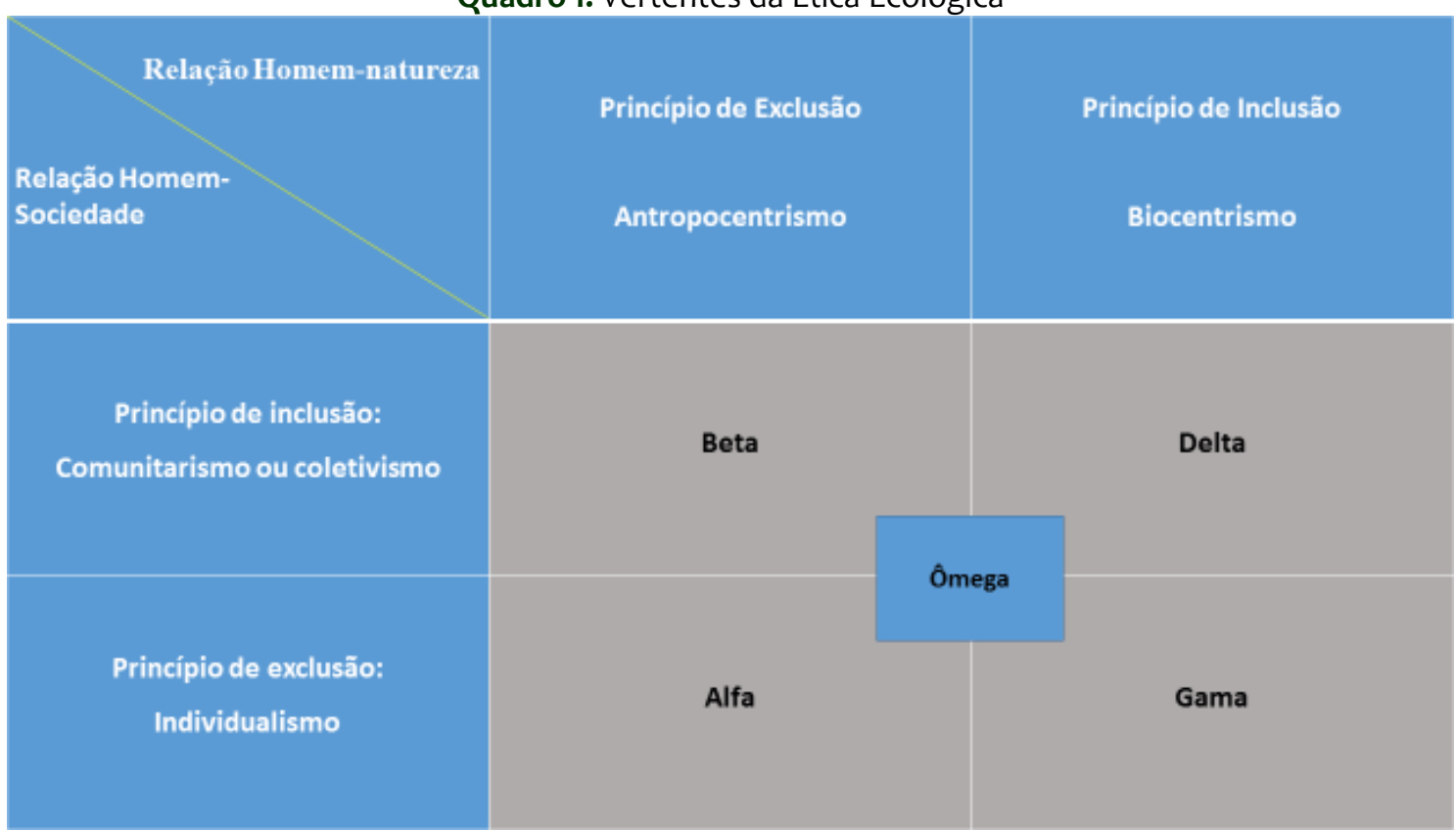

Fonte: LEIS (1996);

Essas várias relações expostas no quadro (que estão em azul) retratam as relações dos seres humanos com a sociedade e com a natureza (antropocentrismo, biocentrismo, coletivismo e individualismo). Além disso, soma-se a essas relações os princípios de inclusão e de exclusão, que implicam em mais quatro divisões (beta, delta, alfa e gama) e também uma quinta, fruto da interseção de todas as quatro (ômega) (LEIS, 1996).

As divisões Alfa e Beta encontram-se no eixo antropocêntrico, logo são permeadas por valores e ações que tendem a privilegiar a humanidade estabelecendo assim uma grande distância entre homem e meio ambiente. Em contrapartida, Delta e Gama encontram-se sob a égide do biocentrismo e com isso defendem uma maior proximidade das pessoas com o meio ecológico, pois estão mais aptas a privilegiar a natureza. Por outro lado, o eixo Alfa e Gama prioriza o indivíduo em detrimento da sociedade, portanto é estabelecida uma distância entre sociedade e o ator individual. Já para Beta e Delta se dá importância ao coletivismo, que procura focar uma maior união dos atores na sociedade. Os cruzamentos destas vertentes propiciam juntar características e cobrir diversas dimensões da ética ecológica (LEIS, 1996).

Feitas as interligações entre as dimensões, Leis explica Alfa, Beta, Gama, Delta e Ômega individualmente. De acordo com o autor, Alfa não requer uma ética totalmente nova, mas apenas vê a questão ambiental como um adjetivo adicionado à ética já existente. 
Propugna a entrada de atores provindos da política e da economia para o ambientalismo, uma vez que esses atores tampouco partem da premissa de criar uma nova ética. A tendência Alfa parte do princípio que as descobertas ambientais precisam apenas ser somadas às ações e atividades existentes, criando então atitudes mais precisas e informadas. Para essa dimensão, o dever dos temas ambientais é apenas mostrar para o ser humano suas responsabilidades ambientais que antes eram negligenciadas. Após isso, o próprio individualismo humano vai optar pela conservação ambiental pois precisa do meio ecológico para sua própria sobrevivência. Em suma, a vertente Alfa tem por base valores e atitudes que delimitam e convergem no individualismo e no antropocentrismo. Não obstante, essa dimensão é a mais próxima das ações e idealismos dominantes na sociedade (LEIS, 1996).

A variante Beta norteia-se pelo viés antropocêntrico, mas diferente da Alfa; prefere o coletivismo ao individualismo. Beta tem a característica de ser mais utópica do que Alfa e também não pressupõe a criação de uma nova ética, mas parte do princípio da mutação de todos os valores individualistas na sociedade, pois segundo essa dimensão o ambientalismo não possui compatibilidade com a lógica competitiva defendida por Alfa. Nesse sentido, Beta critica o capitalismo, a economia, e todo o sistema social que se orienta por princípios hierárquicos ou que cria desigualdades. Para Beta a harmonização da relação homem natureza não pode ser independente da harmonização da relação homem sociedade. Em resumo, Beta prioriza atitudes antropocêntrica e comunitárias (LEIS, 1996).

Gama teve grande aceitação nos anos 1960 e 1970, pois baseando-se no biocentrismo, foram criadas diversas ONGs ambientalistas; nessa época eram as próprias ONGs que representavam o ambientalismo, orientando-se então à tendência Gama. Ao contrário das dimensões anteriores, Gama pretende criar uma nova ética no sentido forte. Mas Gama tem um grande desinteresse por questões sociais, o que implica em uma difícil compreensão, se Gama se orienta mais pelo individualismo ou coletivismo. Entidades como WWF que se preocupam com a fauna e flora são exemplos de tendências Gama. Pode-se enfatizar que Gama representa um grande avanço com relação às interações homemnatureza-sociedade, se comparado à dimensão Alfa (LEIS, 1996).

Essas três tendências explicitadas até o momento, encontram na ciência um grande respaldo, ao contrário da dimensão Delta que se insere mais nas tradições religiosas do que nas questões científicas. Delta possui a característica biocêntrica e comunitária, o que a 
torna a vertente mais utópica e espiritualizada de todas. Diante disso, é a tendência que possui a maior dificuldade em projetar-se na sociedade atual, devido aos seus pressupostos poucos realistas. Delta defende a preservação de todos os seres vivos, tanto humanos como não humanos e reivindica o caráter sagrado de todas as criaturas no mundo (LEIS, 1996).

Por último, Ômega não é considerada por Leis uma vertente mais, mas sim um eixo, um escopo, que age de forma congruente com relação às demais vertentes, ou seja, Ômega tem a função de aglutinar e suscitar coletividade das demais dimensões. Ômega tem função material e espiritual, realista e idealista, procura não dar prioridade a nenhuma vertente, mas criar um equilíbrio entre elas, potencializando ao máximo cada uma das dimensões. Outra compreensão de Ômega é sua capacidade em cruzar diversas tradições culturais, sem que nem uma dessas culturas perca a sua essência. Simultaneamente, a aproximação das mesmas pode criar diversos benefícios, sem conflitos e oposições, mas trabalhando de maneira sinérgica. Em resumo, essa vertente procura destacar a cooperação entre todos, homem-natureza-sociedade (LEIS, 1996).

Al final, Leis (1996) reflete que todas essas vertentes elucidadas têm seus próprios caracteres, e nenhuma delas tem superioridade sobre a outra para atender a atual crise ambiental; ao contrário, todas as dimensões, cada uma à sua maneira ou cooperando entre si, podem ajudar a combater os problemas socioambientais.

\section{DEMAIS CONTRIBUIÇÕES DE HÉCTOR LEIS}

Nessa última sessão, procura-se destacar diversas ideias de Leis envolvendo o tema ambiental. Entre elas, é importante conhecer o pensamento de Leis sobre política e meio ambiente. Para o autor, o meio ambiente foi invisível aos olhos da política até há pouco tempo, porém na atualidade é um ator de grande influência nesse assunto, tendo o poder de mudar decisões políticas e, simultaneamente, também de ser afetado por elas. Mas Leis vai além disso, ele enfatiza que questões socioambientais nos forçam a repensar a política contemporânea e o destino da humanidade (LEIS, 2014). Esse poder do ambientalismo na política pauta-se pelo seu forte idealismo ético e por conseguir realizar ações com princípios idênticos em locais diferentes, com distintos atores (LEIS, 1996). 
Leis e D’Amato (1994) partem do pressuposto que o ambientalismo não tem por prioridade agir como oposição a qualquer posição política ou idealista, mas sim ser um ator integrador de polaridades e de superação de divergências. Pode conceber que a prática ambientalista se encontra entre a expansão do mercado e o colapso da humanidade.

As teorias e práticas ambientais também têm o caráter de se criar e desenvolver realizando a aproximação e harmonização das temáticas espirituais e materiais. Leis ainda defende:

\begin{abstract}
Acreditamos que o ambientalismo é o único movimento, entre todos surgidos na modernidade, que conseguiu nascer e crescer sincreticamente nesses dois mundos da matéria e do espírito. A potencialidade do ambientalismo reside na sua capacidade singular para produzir um encontro entre Dalai Lama, o presidente da General Motors, e Madonna, para tratar de melhorar o estado do planeta (LEIS, 1996, p. 72).
\end{abstract}

Em suma, o ambientalismo tem um projeto que destaca a cooperação entre diversos atores, a utilização de meios sincréticos entres antagonismos políticos, a constante procura do equilíbrio entre disparidades e divergências e a construção de ligações entre realismo e idealismo (LEIS, 1996). Leis também indica que "a mensagem da ecologia poderia reduzir-se a poucas palavras: moderação, equilíbrio, controle" (LEIS, 1996, p.36).

A modernidade é marcada por uma ideologia, o progresso. Esse progresso se reflete na procura ilimitada do novo, algo que acontece na ciência, na tecnologia e no mercado. Essa globalização da ciência, tecnologia e do mercado não respeita os limites ambientais, nem fronteiras socioculturais. Mas o progresso talvez encontra seu melhor instrumento no mercado global, que se expande por todo o globo à procura de novos consumidores, meio de produção e matérias primas para a fabricação de sempre mais produtos (LEIS, 1996). Para Héctor, "o mercado é a verdadeira base de todos os impulsos modernistasprogressistas" (LEIS, 1996, p. 71).

A economia global possui uma dinâmica própria, os movimentos capitalistas são os que determinam os fluxos de capital, restando aos países apenas se adaptarem a isso, pois não possuem controle sobre essa economia global. Diante disso, a crise ambiental espalhou-se pelo mundo através principalmente da globalização da economia, que possui seu próprio jeito de funcionar, não respeitando questões socioambientais (LEIS, 1996). 
A expansão do mercado para o mundo gera uma homogeneização dos hábitos sociais e culturais e também é responsável pela potencialização do individualismo (LEIS, 1996). Leis deixa claro que para ele o mercado encaminha à humanidade para um futuro incerto e perigoso (LEIS, 2014).

Uma das afirmações mais enigmáticas de Leis sobre o ambientalismo é feito pelo autor em seu livro A Modernidade Insustentável. No final do livro o autor afirma:

[...] Depois de completo seu ciclo de formação, o ambientalismo cumpre sua missão histórica morrendo como projeto ou utopia da modernidade, renascendo como aventura civilizatória (LEIS, 2014, p. 206).

Num primeiro momento, nota-se que Leis ressalta que o ciclo de formação do ambientalismo está completo, este ciclo ao qual o autor se refere são as seis dimensões do ambientalismo, detalhadas anteriormente neste artigo, as quais iniciam com a fase estética e terminam com a dimensão espiritual. O autor ressalta que o movimento ambientalista morre como projeto da modernidade. Nesse ponto discorda-se de Leis, pois o ambientalismo ainda continua ativo, através de ONGs como Greenpeace, de movimentos de agricultores familiares que procuram praticar uma agricultura mais sustentável, e até mesmo empresas que, por mais que estejam interessadas no capital financeiro, acabam realizando ações benéficas ao meio ambiente. Diante disso, entende-se que o ambientalismo não morreu. Além disso, discorda-se também dos períodos de início e fim das fases ambientalistas destacadas por Leis, ou seja, os seis momentos históricos do ambientalismo. A estética, a ciência, a sociedade civil, a política, a economia e a espiritualidade são compreendidas pelo autor como fases que se iniciaram em um determinado período e terminaram em outro. Essa afirmação do autor gera controvérsias, pois apesar de essas dimensões ambientalistas iniciarem no período em que o autor destaca, elas não desaparecem, mas continuam ativas de uma forma ou de outra. Um exemplo é a relação entre economia e ecologia; essa ligação ainda existe, apesar de o conceito de sustentabilidade ter sido amplamente (mas não inteiramente) "tirado de cena", outros conceitos como economia verde ou modernização ecológica ainda têm mantido a conexão entre economia e meio ambiente. Portanto, muitas fases ambientalistas não desapareceram como pressupõe Leis. 
O autor entende que o ambientalismo de caráter mais utópico ou idealista já não existe, o que também não condiz com o pensamento atual, pois muitas ideologias e utopias ainda são mantidas pelo ambientalismo.

Por último, Leis ressalta que o ambientalismo renasce como uma aventura civilizatória. Compreende-se nesse aspecto que depois do ambientalismo ter cumprido uma missão de caráter mais idealista na modernidade, renasce como uma aventura, ou seja, como algo que vai ser vivido pela sociedade. Se Leis entendeu dessa forma, concordase com o autor, pois a sociedade se encontra em um momento em que é necessário não apenas refletir filosoficamente sobre o meio ambiente (apesar de que isso também é importante), mas também praticar ações que favoreçam a questão ambiental.

Para encerrar o pensamento de Leis, enfatiza-se o prefácio escrito pelo autor para o lançamento da segunda edição do livro A Modernidade Insustentável lançado em 2014. Nesse prefácio o autor argumenta que o ambientalismo atual está longe de sua gênese, ou seja, baseia-se apenas no racional acreditando que a maioria das soluções advirão apenas da técnica, da tecnologia e da ciência. No seu passado, o ambientalismo, além de requerer soluções tecnológicas, também representava uma luta contra os valores consumistas, materialistas e individualistas da sociedade. Devido a esse preceito, é preponderante que os atores que lutam pela causa ambiental na atualidade se lembrem do ambientalismo do passado, para que possam focar uma mutação não apenas nas tecnologias, mas também na forma de pensar.

\section{CONSIDERAÇÕES FINAIS}

A finalidade desse artigo foi expor e refletir sobre as contribuições do autor Héctor Ricardo Leis com relação à temática ambiental. Entende-se que a principal contribuição do autor foi pensar o tema meio ambiente sob novos olhares, como por exemplo através da filosofia e teologia. Além disso, fica evidente que o autor propõe novos meios de solucionar a crise ambiental, a destacar: o princípio do amor, da hierarquia e a ajuda da religião. Leis procura entender um pouco melhor a ética ecológica da modernidade e também realiza críticas com relação ao mercado e ao princípio de igualdade.

Em suma, o autor ressalta inúmeras contribuições, algumas ainda incipientes, outras precisando de releituras para serem melhoradas, e algumas que já estariam "prontas" para 
auxiliar a encontrar soluções para a problemática ambiental. Leis enfatiza que a evolução social depende fortemente do modelo civilizatório adotado, e que esse determinado modelo é uma resposta que a sociedade atribui a algum problema que precisa ser solucionado. Entende-se que o ambientalismo é uma resposta à crise ambiental da atualidade, portando o modelo de sociedade a ser adotado deve ser ecológico. Para isso acontecer, ideias de autores que estudam o meio ambiente igual a Leis, devem ser estudadas, criticadas e melhoradas, para que possam serem aplicadas no âmbito social.

\section{REFERÊNCIAS}

CAVALCANTI, C. Concepções da economia ecológica: suas relações com a economia dominante e a economia ambiental, Revista Estudos Avançados, São Paulo, V. 24, n. 68, p. 53-68, fev./fev. 2010. Disponível em < http://www.scielo.br/pdf/ea/v24n68/07.pdf > Acesso em: 15 janeiro 2016.

LEIS, H.R. A modernidade insustentável: as críticas do ambientalismo à sociedade contemporânea. 3. ed. São Paulo. Annablume, 2014. 238p.

LEIS, H.R. O labirinto: ensaios sobre ambientalismo e globalização. São Paulo-Blumenau. Editora FURB- GAIA. 1996. 171p.

LEIS, H.R; D’AMATO, J.L. Contribuição para uma teoria das práticas do ambientalismo. Revista de Ciências Humanas. Florianópolis, V. 14, n. 19, p. 9-43. 1996. Disponível em:< https://periodicos.ufsc.br/index.php/revistacfh/article/view/23497/21164> Acesso em: 26 de julho 2016.

LEIS, H.R; D'AMATO, J.L. O ambientalismo como movimento vital: Análise de suas dimensões histórica, ética e vivencial. In. Cavalcanti, Clovis (Org). Desenvolvimento e natureza: estudos para uma sociedade sustentável. Recife, 1994. p. 77-103.

LEIS, H.R. O ambientalismo como fim da modernidade? Travessia-revista de literatura. Florianópolis, n. 31, p. 65-75. 1996. Disponível em:< https://periodicos.ufsc.br/index.php/travessia/article/view/16837/15416> Acesso em: 28 de julho 2016.

LEIS, H.R. Uma viagem interdisciplinar ao lado oculto da problemática ambiental na modernidade. Revista Internacional Interdisciplinar- Interthesis. Florianópolis, V.7, n.02, p. 19-44, jul/dez.2010. Disponível em:< https://periodicos.ufsc.br/index.php/interthesis/article/view/1807-1384.2010v7n2p19> Acesso em: 23 de julho 2016.

LEIS, H.R. Meio Ambiente, ética e religião na sociedade contemporânea. Revista de Educação, Cultura e Meio Ambiente. Porto Velho, V.03, n.15, p.01-12. 1999. Disponível em:< 
http://www.revistapresenca.unir.br/artigos_presenca/15Héctorricardoleis_meioambiente eticaereligiaonasociedadecontemporanea.pdf> Acesso em 22 de julho 2016.

SEIFFERT, M. E. B. Gestão ambiental instrumentos, esferas de ação e educação ambiental. São Paulo, Editora Atlas, 2007. 310 p. 